\title{
Gap junction inhibition by heptanol increases ventricular arrhythmogenicity by reducing conduction velocity without affecting repolarization properties or myocardial refractoriness in Langendorff-perfused mouse hearts
}

\author{
GARY TSE $^{1}$, JIE MING YEO ${ }^{2}$, VIVIAN TSE $^{3}$, JOSEPH KWAN $^{4}$ and BING SUN ${ }^{5}$ \\ ${ }^{1}$ Department of Medicine and Therapeutics, Chinese University of Hong Kong, Hong Kong, P.R. China; ${ }^{2}$ Faculty of Medicine, \\ Imperial College London, London SW7 2AZ, UK; ${ }^{3}$ Department of Physiology, McGill University, Montreal, QC H3G 1Y6, \\ Canada; ${ }^{4}$ Department of Medicine, Li Ka Shing Faculty of Medicine, University of Hong Kong, Hong Kong; \\ ${ }^{5}$ Department of Cardiology, Tongji University Affiliated Tongji Hospital, Shanghai 200065, P.R. China
}

Received May 4, 2016; Accepted July 18, 2016

DOI: $10.3892 / \mathrm{mmr} .2016 .5738$

\begin{abstract}
In the current study, arrhythmogenic effects of the gap junction inhibitor heptanol $(0.05 \mathrm{mM})$ were examined in Langendorff-perfused mouse hearts. Monophasic action potential recordings were obtained from the left ventricular epicardium during right ventricular pacing. Regular activity was observed both prior and subsequent to application of heptanol in all of the 12 hearts studied during $8 \mathrm{~Hz}$ pacing. By contrast, induced ventricular tachycardia (VT) was observed after heptanol treatment in 6/12 hearts using a S1S2 protocol (Fisher's exact test; $\mathrm{P}<0.05$ ). The arrhythmogenic effects of heptanol were associated with increased activation latencies from $13.2 \pm 0.6$ to $19.4 \pm 1.3 \mathrm{msec}$ (analysis of variance; $\mathrm{P}<0.001$ ) and reduced conduction velocities $(\mathrm{CVs})$ from $0.23 \pm 0.01$ to $0.16 \pm 0.01 \mathrm{msec}$ (analysis of variance; $\mathrm{P}<0.001$ ) in an absence of alterations in action potential durations (ADPs) at $\mathrm{x}=90 \%(38.0 \pm 1.0$ vs. $38.3 \pm 1.8 \mathrm{msec}), 70 \%(16.8 \pm 1.0 \mathrm{vs}$. $19.5 \pm 0.9 \mathrm{msec}), 50 \%(9.2 \pm 0.8 \mathrm{vs} .10 .1 \pm 0.6 \mathrm{msec})$ or $30 \%$ $(4.8 \pm 0.5$ vs. $6.3 \pm 0.6 \mathrm{msec})$ repolarization $\left(\mathrm{APD}_{\mathrm{x}}\right)$ or in effective refractory period (ERPs) $(39.6 \pm 1.9$ vs. $40.6 \pm 3.0 \mathrm{msec})$ (all $\mathrm{P}>0.05)$. Consequently, excitation wavelengths $(\lambda ; \mathrm{CV} \times \mathrm{ERP})$ were reduced from $9.1 \pm 0.6$ to $6.5 \pm 0.6 \mathrm{~mm}(\mathrm{P}<0.01)$, however critical intervals for re-excitation $\left(\mathrm{APD}_{90}-\mathrm{ERP}\right)$ were unaltered $(-1.1 \pm 2.4$ vs. $-2.3 \pm 1.8 \mathrm{msec} ; \mathrm{P}>0.05)$. Together, these observations demonstrate for the first time, to the best of our knowledge, that inhibition of gap junctions alone using a low heptanol concentration $(0.05 \mathrm{mM})$ was able to reduce $\mathrm{CV}$,
\end{abstract}

Correspondence to: Dr Gary Tse, Department of Medicine and Therapeutics, Chinese University of Hong Kong, 30-32 Ngan Shing Street, Hong Kong, P.R. China

E-mail: gary.tse@doctors.org.uk

Key words: conduction, conduction velocity, repolarization, refractory period, wavelength, gap junction, arrhythmia which alone was sufficient to permit the induction of VT using premature stimulation by reducing $\lambda$, which therefore appears central in the determination of arrhythmic tendency.

\section{Introduction}

An orderly spread of action potentials through the heart is critical for normal electrical function and its disruption can lead to cardiac arrhythmias (1). Experiments in pre-clinical models have advanced understanding of the electrophysiological mechanisms underlying arrhythmogenesis using genetic and pharmacological approaches (1-24). Experiments in mouse models have highlighted the role of gap junctions in ventricular conduction and arrhythmogenesis, however the results have been controversial. Heterozygous $\mathrm{Cx} 43^{+/-}$mice were demonstrated to exhibit at $45-50 \%$ reduction in $\mathrm{Cx} 43$ expression, however, the degree of conduction velocity (CV) slowing was variable: CV was either unchanged (25-30) or reduced by 23-44\% (31-33). Additional experiments used a pharmacological approach, demonstrating ventricular arrhythmogenesis associated with reduced CV using $2 \mathrm{mM}$ heptanol (7). This agent inhibits gap junctions specifically at concentrations up to $1-2 \mathrm{mM}(34,35)$ however at $\geq 2 \mathrm{mM}$ additionally inhibits sodium channels $(34,36)$. The extent to which the conduction defects and arrhythmogenesis observed could be attributed to loss of gap junction coupling alone remains to be fully elucidated.

Therefore, the aims of the present study were to examine the possible role of abnormal gap junction function in ventricular arrhythmogenesis, by applying heptanol at a low concentration that specifically targets gap junctions $(0.05 \mathrm{mM})$. At this concentration, it was identified that heptanol did not elicit spontaneous arrhythmias during regular pacing, however increased the incidence of ventricular tachycardia induced by a S1S2 protocol. This was associated with increased activation latencies in an absence of alterations in either action potential durations (APDs) or effective refractory periods (ERPs). The observations of the present study suggest that loss of gap 
junction function alone is sufficient to produce conduction slowing and ventricular arrhythmogenesis.

\section{Materials and methods}

Solutions. The experiments described in this study used Krebs-Henseleit solution (composition in $\mathrm{mM}$ : $\mathrm{NaCl} 119, \mathrm{NaHCO}_{3} 25, \mathrm{KCl} 4, \mathrm{KH}_{2} \mathrm{PO}_{4} 1.2, \mathrm{MgCl}_{2} 1$, $\mathrm{CaCl}_{2} 1.8$, glucose 10 and sodium pyruvate $2 ; \mathrm{pH} 7.4$ ) that had been bicarbonate-buffered and bubbled with $95 \% \mathrm{O}_{2} / 5 \%$ $\mathrm{CO}_{2}$ (37). Heptanol (0.82 $\mathrm{g} \mathrm{ml}^{-1}$; Sigma-Aldrich, Haverhill, $\mathrm{UK}$ ) is soluble in aqueous solutions up to $9 \mathrm{mM}$ (https://www. rsc.org/merck-index), and was diluted using Krebs-Henseleit solution to produce a final concentration of $0.05 \mathrm{mM}$.

Preparation of Langendorff-perfused mouse hearts. A total of 13 wild-type mice of genetic background 129 (5 and 7 months of age, 3 male, 10 female; weight, $39.2 \pm 1.9 \mathrm{~g}$ ) were used in the current study. The animals were maintained at room temperature $\left(21 \pm 1^{\circ} \mathrm{C}\right)$ and were subjected to a $12: 12 \mathrm{~h}$ light/dark cycle with free access to sterile rodent chow and water in an animal facility. The experiments described here were compliant with the UK Animals (Scientific Procedures) Act 1986. The present study was approved by the Animal Welfare and Ethical Review Body at University of Cambridge. (Cambridge, UK) The procedures for the preparation of Langendorff-perfused mouse hearts were as follows: Mice were sacrificed by cervical dislocation in accordance with Sections 1 (c) and 2 of Schedule 1 of the UK Animals (Scientific Procedures) Act 1986. The hearts were rapidly excised and immediately submerged in ice-cold Krebs-Henseleit solution. Cannulation of the aorta was achieved using a tailor-made 21-gauge cannula that had been prefilled with ice-cold buffer. Using a micro-aneurysm clip (Harvard Apparatus, Cambridge, UK), the heart was securely attached to the perfusion system. Retrograde perfusion was initiated at a rate of 2-2.5 $\mathrm{ml} \mathrm{min}^{-1}$ using a peristaltic pump (Model 505S Bredel Pump; Watson-Marlow, Ltd., Falmouth, UK) with the perfusate passing through 200 and $5 \mu \mathrm{m}$ filters successively, and heated to $37^{\circ} \mathrm{C}$ using a water jacket and circulator prior to reaching the aorta. The hearts that regained their pink colour and spontaneous rhythmic activity were studied further (approximately 90\%). The remaining $10 \%$ were discarded. Perfusion took place for a further $20 \mathrm{~min}$ to minimise any residual effects of catecholamine released endogenously, prior to electrophysiological analysis of the hearts.

Stimulation protocols. Electrical stimulation was achieved using paired platinum electrodes (1 $\mathrm{mm}$ interpole distance) placed at the right ventricular epicardium. This took place at $8 \mathrm{~Hz}$, using square wave pulses $2 \mathrm{msec}$ in duration, with a stimulation voltage set to three times the diastolic threshold (Grass S48 Square Pulse Stimulator; Grass-Telefactor; Astro Med, Inc., Slough, UK) immediately subsequent to the start of perfusion. The S1S2 protocol was used to assess arrhythmogenicity and identify re-entrant substrates. This consisted of a drive train of 8 regularly paced S1 stimuli separated by a $125 \mathrm{msec}$ basic cycle length (BCL), followed by premature S2 extra stimuli every ninth stimulus. The S1S2 interval was first set to $125 \mathrm{msec}$ and then successively reduced by $1 \mathrm{msec}$ with each nine stimulus cycles until arrhythmic activity was initiated or refractoriness was reached, whereupon the S2 stimulus elicited no ventricular response.

Recording procedures. Monophasic action potential (MAP) recordings from the left ventricular epicardium were obtained using a MAP electrode (Linton Instruments; Harvard Apparatus). MAPs from the left ventricular endocardium were obtained using a custom-made MAP electrode that was made from two strands of $0.25 \mathrm{~mm}$ Teflon-coated silver wire $(99.99 \%$ purity; Advent Research Materials, Ltd., Witney, UK). To eliminate direct current offset, the electrode tips were galvanically chlorided. The stimulating and recording electrodes were maintained at constant positions, with an inter-electrode distance of $3 \mathrm{~mm}$. This allowed CVs to be determined from the activation latencies. All recordings were performed using a BCL of $125 \mathrm{msec}(8 \mathrm{~Hz})$ to exclude rate-dependent differences in APDs. MAPs were pre-amplified using a NL100AK head stage, amplified with a NL104A amplifier and band pass filtered between $0.5 \mathrm{~Hz}$ and $1 \mathrm{kHz}$ using a NL125/6 filter (Neurolog; Digitimer, Ltd., Welwyn Garden City, UK) and then digitized (1401plus MKII; Cambridge Electronic Design, Ltd., Cambridge, UK) at $5 \mathrm{kHz}$. They were then analysed using Spike2 version 5.11 software (Cambridge Electronic Design, Ltd.). MAP waveforms that did not match the previous established stringent criteria for MAP signals were rejected (38). They must have stable baselines, fast upstrokes, with no inflections or negative spikes, and a rapid first phase of repolarization. $0 \%$ repolarization was measured at the peak of the MAP and $100 \%$ repolarization was measured at the point of return of the potential to baseline (38-40).

The following parameters were obtained from the experimental records: i) Activation latency, defined as the time difference between the stimulus and the peak of the MAP; ii) CV, as the ratio of the inter-electrode distance to the activation latency. As the latter distance was kept constant, CVs were inversely proportional to the corresponding activation latencies; iii) $\mathrm{APD}_{\mathrm{x}}$, the time difference between the peak of the MAP and $\mathrm{x}=30,50,70$ and $90 \%$ repolarization; iv) ERP, defined as the longest S1S2 interval at which the S2 extra stimulus failed to initiate a ventricular signal during programmed electrical stimulation; v) excitation wavelength, $\lambda$, given by $\mathrm{CV} \times \mathrm{ERP}$; vi) critical intervals for re-excitation given by $\mathrm{APD}_{90}-\mathrm{ERP}$.

Statistical analysis. All values are expressed as the mean \pm standard error. Categorical data were compared with Fisher's exact test (one-tailed) using OriginPro version 8 (OriginLab Corporation, Northampton, MA, USA). Different experimental groups were compared by one-way analysis of variance. $\mathrm{P}<0.05$ was considered to indicate a statistically significant difference. $\mathrm{P}<0.05,0.01$ and 0.001 were denoted by * ${ }^{* *}$ and ${ }^{* * *}$, respectively.

\section{Results}

Ventricular arrhythmogenicity and its association with action potential activation and recovery properties were examined prior and subsequent to introduction of $0.05 \mathrm{mM}$ heptanol in Langendorff-perfused mouse hearts. The right ventricular 
epicardium was electrically stimulated using either regular $8 \mathrm{~Hz}$ or S1S2 pacing $(2,3,5,7,12)$. MAP recordings were obtained from the left ventricular epicardium. The stimulating and recording electrodes were maintained at a constant distance of $3 \mathrm{~mm}$, which permitted CVs to be estimated from the respective activation latencies. Ventricular tachycardia (VT) was defined as a series of $\geq 5$ action potentials with coupling intervals closer than the BCL.

Heptanol at $0.05 \mathrm{mM}$ exerts ventricular pro-arrhythmic effects during S1S2, however not during regular pacing. The initial experiments conducted during regular pacing demonstrated consistent ventricular activity in the absence of spontaneous arrhythmias in all of the 12 hearts studied, whether prior or subsequent to introduction of $0.05 \mathrm{mM}$ heptanol, or following removal of heptanol from the perfusate (Fig. 1). The second set of experiments then applied a S1S2 pacing protocol, which imposed extra systolic S2 stimuli following trains of regular S1 pacing stimuli. The S1S2 interval was initially at the BCL and subsequently reduced by $1 \mathrm{msec}$ with each cycle until the S2 stimuli produced either arrhythmic activity or refractoriness. The latter indicating that the ERP was reached. None of the hearts studied demonstrated evidence of inducible arrhythmias prior to application of the test agent (Fig. 2A). By contrast, it was possible to induce VT subsequent to application of heptanol (Fig. 2B). The incidences of inducible VT prior and subsequent to introduction of heptanol, and following its withdrawal from the perfusing solution are summarized in Fig. 2C, indicating that heptanol exerted significant pro-arrhythmic effects, as the extra stimuli were able to induce VT in $6 / 12$ hearts $\left({ }^{*} \mathrm{P}<0.05\right.$; Fisher's exact test).

Pro-arrhythmic effects of heptanol were associated with reduced CVs in an absence of alterations in APDs or ERPs. Previous studies in mouse models have associated increased arrhythmogenicity with reduced CVs, prolonged or shortened APDs and reduce ERPs $(2,3,5,7,12)$. These values were therefore obtained from the experimental recordings described above. Thus, heptanol increased activation latencies from $13.2 \pm 0.6$ to $19.4 \pm 1.3 \mathrm{msec}$ (Fig. 3A; analysis of variance; $\mathrm{P}<0.001$ ) and reduced $\mathrm{CVs}$ from $0.23 \pm 0.01$ to $0.16 \pm 0.01 \mathrm{msec}$ (Fig. $3 \mathrm{~B} ; \mathrm{P}<0.001$ ), without altering $\mathrm{APD}_{90}(38.0 \pm 1.0$ vs. $38.3 \pm 1.8 \mathrm{msec}$; Fig. $3 \mathrm{C}), \mathrm{APD}_{70}(16.8 \pm 1.0$ vs. $19.5 \pm 0.9 \mathrm{msec}$; Fig. $3 \mathrm{D}), \mathrm{APD}_{50}(9.2 \pm 0.8$ vs. $10.1 \pm 0.6 \mathrm{msec}$; Fig. $3 \mathrm{E}), \mathrm{APD}_{30}(4.8 \pm 0.5$ vs. $6.3 \pm 0.6 \mathrm{msec}$; Fig. $3 \mathrm{~F})$ or ERPs $(39.6 \pm 1.9$ vs. $40.6 \pm 3.0$ msec; Fig. $3 \mathrm{G})$.

Pro-arrhythmic effects of heptanol were associated with reduced excitation wavelengths despite unaltered critical intervals. Reductions in excitation wavelengths ( $\lambda$; CV x ERP) and increases in critical intervals for re-excitation $\left(\mathrm{APD}_{90}-\mathrm{ERP}\right)$ have been associated with increased arrhythmogenicity $(7,41)$. Accordingly, these parameters were calculated for the hearts used in the current study. Heptanol reduced $\lambda$ from $9.1 \pm 0.6$ to $6.5 \pm 0.6 \mathrm{~mm}$ (Fig. $4 \mathrm{~A} ; \mathrm{P}<0.01$ ) without altering critical intervals ( $-1.1 \pm 2.4$ vs. $-2.3 \pm 1.8 \mathrm{msec}$; Fig. 4B).

\section{Discussion}

Sudden cardiac death (SCD) is a significant problem and is responsible for around 60,000 deaths in the UK (42), 200,000
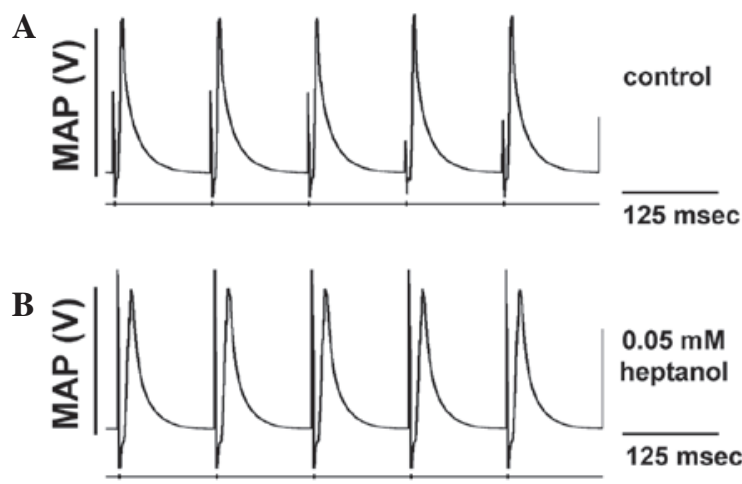

Figure 1. Stable MAPs obtained during regular $8 \mathrm{~Hz}$ pacing (A) prior to and (B) subsequent to introduction of $0.05 \mathrm{mM}$ heptanol. MAP, monophasic action potential.
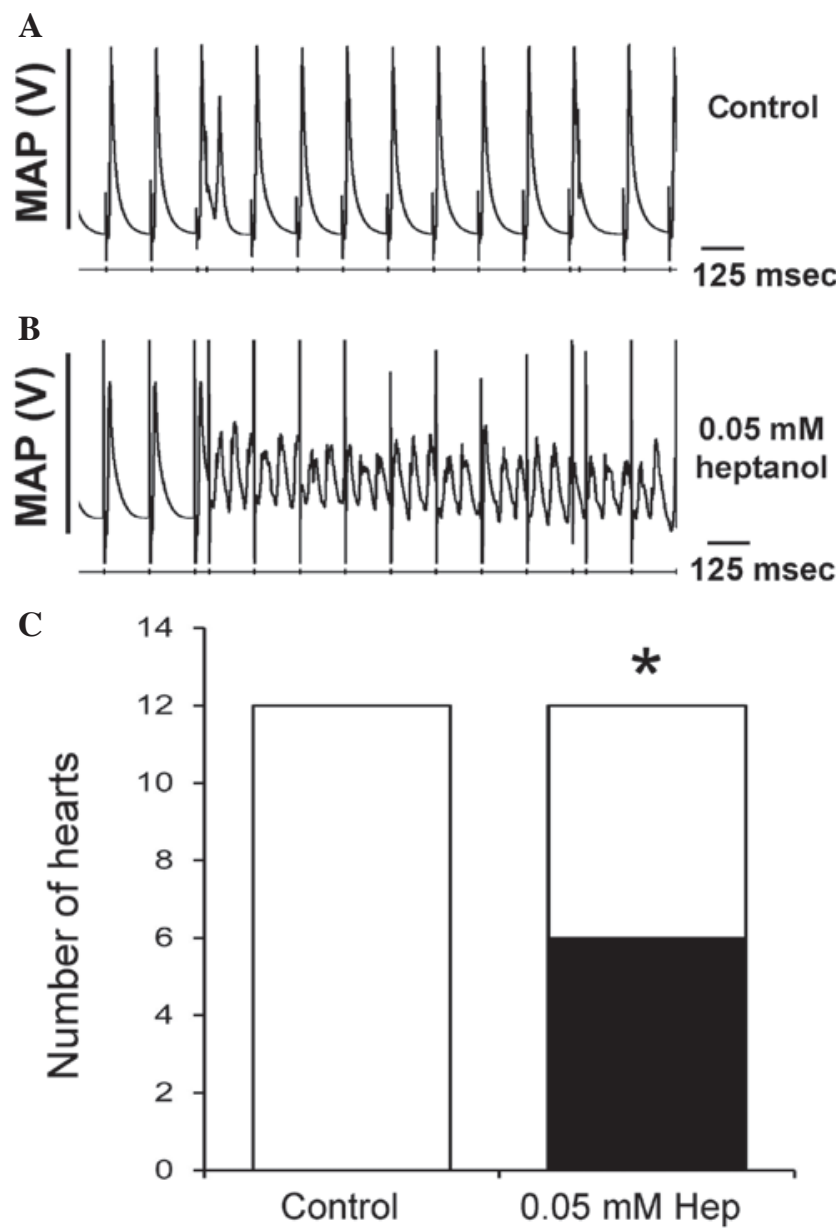

Figure 2. (A) Refractory outcomes observed prior to the introduction of the test agent and (B) the induced ventricular tachycardia following introduction of $0.05 \mathrm{mM}$ Hep during S1S2 pacing. (C) Number of hearts showing refractory (clear bar) or arrhythmic (black bar) outcomes. ${ }^{*} \mathrm{P}<0.05$ vs. control. Hep, heptanol; MAP, monophasic action potential.

deaths in the US (43) and 4-5 million deaths globally (44) per year. It has been suggested that SCD arises from the development of malignant ventricular arrhythmias, the electrophysiological mechanisms of which remain to be fully understood. Mouse hearts have been used to study arrhythmogenesis as they are amenable to both genetic and pharmacological manipulation. 

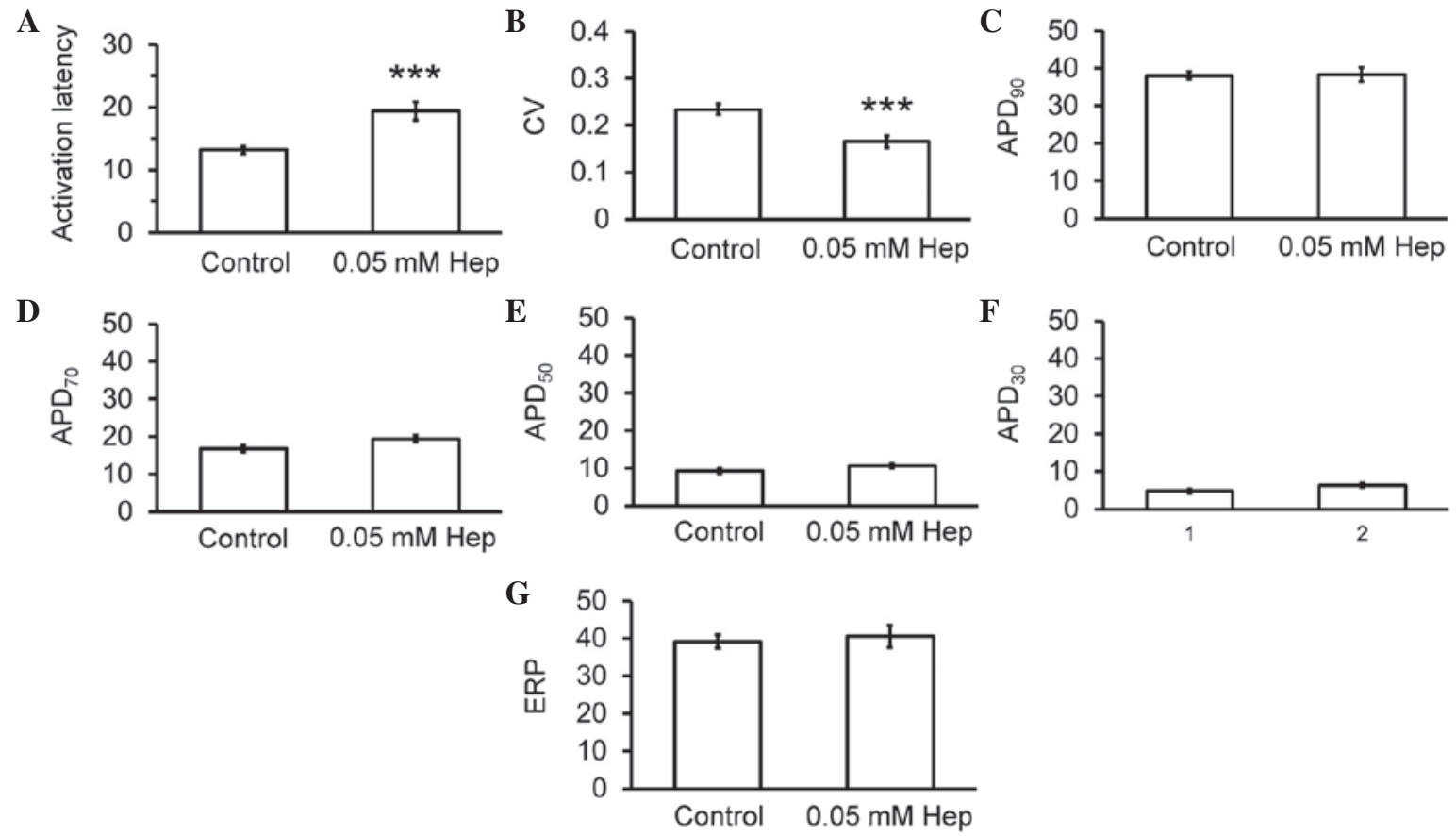

Figure 3. Hep (0.05 mM) increased (A) activation latencies and (B) reduced CV values without affecting APD values at (C) $90 \%$, (D) $70 \%$, (E) $50 \%$ or (F) $30 \%$ repolarization $\left(\mathrm{APD}_{\mathrm{x}}\right)$, or $(\mathrm{G})$ ERPs. ${ }^{* * *} \mathrm{P}<0.001 ; \mathrm{Hep}$, heptanol; $\mathrm{CV}$, conduction velocity; APD, action potential duration; ERP, effective refractory period.

A

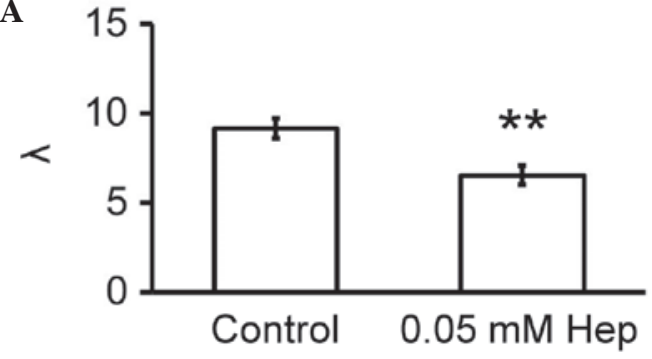

B

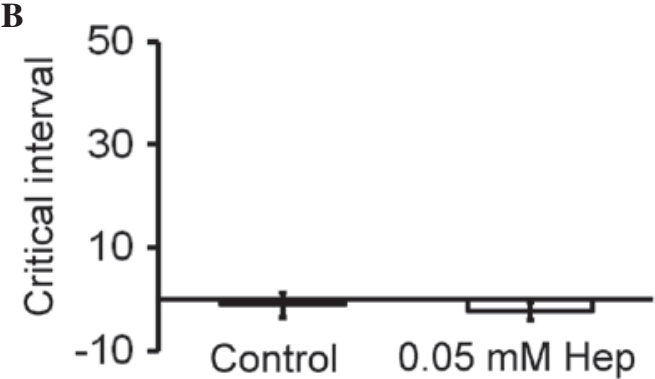

Figure 4. Hep (0.05 mM) (A) reduced excitation wavelengths ( $\lambda$; CV x ERP), (B) without altering critical intervals for re-excitation (CI, $\left.\mathrm{APD}_{90}-\mathrm{ERP}\right)$. ${ }^{* *} \mathrm{P}<0.01$ vs. control. Hep, heptanol; CV, conduction velocity; ERP, effective refractory period.

Propagation of the action potentials through the working myocardium depends on sodium channel activation followed by gap junction conduction. Gap junctions are hexameric proteins made of connexins mediate intercellular coupling by allowing passive electrotonic spread of ions and of larger molecules (45). Their resistance contributes to axial resistance and modulates CV $(46,47)$. Cx43 is the isoform present in ventricles, and the effects of loss of $\mathrm{Cx} 43$ on ventricular conduction and arrhythmogenesis have been extensively studied in mouse models $(25-33,48,49)$, however, with significant disagreement between the results of these studies (28). Thus, cardiac-restricted $\mathrm{Cx} 43$ inactivation followed by crossing with Cre recombinase produced mosaic mice, in which Cx43 was observed to be educed by up to $95 \%$ when compared with wild-type mice (48). Additional experiments identified that heterozygous $\mathrm{Cx}_{4} 3^{+/-}$mice exhibited a $45-50 \%$ reduction in $\mathrm{Cx} 43$ expression. In these mice, $\mathrm{CV}$ was either unchanged (25-30) or reduced by $23-44 \%$ (31-33). These studies suggest different parameters, including interstitial volume (50), width of the perinexus, intracellular calcium concentrations, perfusate composition and osmolarity (28), have additional effects on cardiac conduction. Pharmacological methods have additionally been used to study the role of gap junctions in arrhythmogenesis. A previous study reported that $2 \mathrm{mM}$ heptanol exerted significant pro-arrhythmic effects by reducing CVs without influencing APDs, however increased ERPs (7). These alterations led to reduced excitation wavelength ( $\lambda$; CV $\mathrm{x}$ ERP), which is consistent with the increased likelihood of re-entry. Heptanol is an agent that reversibly inhibits gap junctions at concentrations up to $1 \mathrm{mM}$ and also sodium channels at concentrations $\geq 2 \mathrm{mM}(34,36)$. It was therefore not possible to determine the relative contributions of gap junction uncoupling vs. reduced sodium channel function in the reduction of $\mathrm{CV}$ and the ventricular arrhythmogenesis observed. Furthermore, $2 \mathrm{mM}$ heptanol produced not only CV slowing, however additionally increased ERPs. The latter observation is consistent with its effects on sodium channel kinetics of producing a depolarizing shift of the activation curve, and a hyperpolarizing shift of the inactivation curve, which would reduce the sodium window current (36). Increasing ERP alone is suggested to be anti-arrhythmic via the increase in $\lambda$, regional increases in ERP could theoretically predispose to re-entry by producing refractory obstacles 
around which action potentials can circulate, and areas of unidirectional conduction block (51).

Therefore, the present experiments were conducted to determine whether heptanol at a concentration that specifically inhibits gap junctions $(0.05 \mathrm{mM})(34,36)$ could produce pro-arrhythmic effects. Its application resulted in an increased incidence of inducible, however not spontaneous, arrhythmias, which was associated with increased activation latencies and reduced CVs, in an absence of alterations in APDs or ERPs. Together, these alterations led to a reduced excitation wavelength $(\lambda)$ despite leaving critical intervals unaltered. These results are consistent with previous observations that inhibition of gap junctions and sodium channels at $2 \mathrm{mM}$ heptanol resulted in a greater degree of $\mathrm{CV}$ slowing compared with the low concentration used in the current study, and increased ERPs. Under these conditions, spontaneous and provoked VT were observed. In the present study, gap junction inhibition alone using $0.05 \mathrm{mM}$ heptanol did not elicit spontaneous VT during regular pacing.

As the aim of this study was to examine the effects of reducing gap junction coupling, it was therefore appropriate to use the MAP method. This method has been extensively used to study cardiac electrophysiology in animal systems $(8,52-59)$. For future experiments, the measurement of magnetic signals may be beneficial. It has been previously demonstrated to useful for characterizing cardiac structural abnormalities (60-62), and observed that functional mapping could be achieved using magnetocardiography in mouse models. Thus, it is suggested that its use in assessing abnormal cardiac electrophysiology in mice warrants future investigation (63-66).

In conclusion, the current study demonstrated that gap junction inhibition by heptanol alone was sufficient to reduce CV without affecting APD or ERP, and the consequent reduction in $\lambda$ was suggested to be responsible for the arrhythmogenesis observed.

\section{Acknowledgements}

Dr Gary Tse was awarded a BBSRC Doctoral Training Award from the University of Cambridge (Cambridge, UK).

\section{References}

1. Tse G: Both transmural dispersion of repolarization and transmural dispersion of refractoriness are poor predictors of arrhythmogenicity: A role for the index of Cardiac Electrophysiological Balance (QT/QRS)? J Geriatr Cardiol, 2016.

2. Tse G, Tse V and Yeo JM: Ventricular anti-arrhythmic effects of heptanol in hypokalaemic, Langendorff-perfused mouse hearts. Biomed Rep 4: 313-324, 2016.

3. Tse G, Tse V, Yeo JM and Sun B: Atrial anti-arrhythmic effects of heptanol in Langendorff-perfused mouse hearts. PLoS One 11: e0148858, 2016.

4. Tse G: Mechanisms of cardiac arrhythmias. J Arrhythm 32: 75-81, 2016.

5. Tse G, Wong ST, Tse V and Yeo JM: Restitution analysis of alternans using dynamic pacing and its comparison with S1S2 restitution in heptanol-treated, hypokalaemic Langendorff-perfused mouse hearts. Biomed Rep 4: 673-680, 2016.

6. Tse G and Yeo JM: Conduction abnormalities and ventricular arrhythmogenesis: The roles of sodium channels and gap junctions. Int J Cardiol Heart Vasc 9: 75-82, 2015.

7. Tse G, Hothi SS, Grace AA and Huang CL: Ventricular arrhythmogenesis following slowed conduction in heptanol-treated, Langendorff-perfused mouse hearts. J Physiol Sci 62: 79-92, 2012 .
8. Tse G, Wong ST, Tse V and Yeo JM: Monophasic action potential recordings: Which is the recording electrode? J Basic Clin Physiol Pharmacol, 2016.

9. Tse G, Lai TH, Yeo JM, Tse V and Wong SH: Mechanisms of electrical activation and conduction in the gastrointestinal system: Lessons from cardiac electrophysiology. Front Physiol 7: $182,2016$.

10. Tse G, Wong ST, Tse V and Yeo JM: Depolarization vs. repolarization: What is the mechanism of ventricular arrhythmogenesis underlying sodium channel haploinsufficiency in mouse hearts? Acta Physiol (Oxf), 2016

11. Chen Z, Sun B, Tse G, Jiang J and Xu W: Reversibility of both sinus node dysfunction and reduced HCN4 mRNA expression level in an atrial tachycardia pacing model of tachycardia-bradycardia syndrome in rabbit hearts. Int J Clin Exp Pathol 9, 2016.

12. Tse G, Sun B, Wong ST, Tse V and Yeo JM: Ventricular anti-arrhythmic effects of hypercalcaemia treatment in hyperkalaemic, Langendorff-perfused mouse hearts. Biomed Rep 4:313-324, 2016

13. Tse G, Lai ET, Tse V and Yeo JM: Molecular and electrophysiological mechanisms underlying cardiac arrhythmogenesis in diabetes mellitus. J Diabetes Res, 2016. (In press)

14. Tse G, Wong ST, Tse V and Yeo JM: Determination of action potential wavelength restitution in $\mathrm{Scn} 5 \mathrm{a}+/-$ mouse hearts modelling human Brugada syndrome. J Physiol, 2016. (In press)

15. Osadchii OE: Flecainide-induced proarrhythmia is attributed to abnormal changes in repolarization and refractoriness in perfused guinea-pig heart. J Cardiovasc Pharmacol 60: 456-466, 2012.

16. Osadchii OE: Quinidine elicits proarrhythmic changes in ventricular repolarization and refractoriness in guinea-pig. Can J Physiol Pharmacol 91: 306-315, 2013.

17. Wilde AA, Postema PG, Di Diego JM, Viskin S, Morita H, Fish JM and Antzelevitch C: The pathophysiological mechanism underlying Brugada syndrome: Depolarization versus repolarization. J Mol Cell Cardiol 49: 543-553, 2010.

18. Osadchii OE: Impact of hypokalemia on electromechanical window, excitation wavelength and repolarization gradients in guinea-pig and rabbit hearts. PLoS One 9: e105599, 2014.

19. Osadchii OE: Impaired epicardial activation-repolarization coupling contributes to the proarrhythmic effects of hypokalaemia and dofetilide in guinea pig ventricles. Acta Physiol (Oxf) 211: 48-60, 2014.

20. Hsieh YC, Lin JC, Hung CY, Li CH, Lin SF, Yeh HI, Huang JL, Lo CP, Haugan K, Larsen BD and Wu TJ: Gap junction modifier rotigaptide decreases the susceptibility to ventricular arrhythmia by enhancing conduction velocity and suppressing discordant alternans during therapeutic hypothermia in isolated rabbit hearts. Heart Rhythm 13: 251-261, 2016.

21. Hsieh YC, Lin SF, Huang JL, Hung CY, Lin JC, Liao YC, Lo CP, Wang KY and Wu TJ: Moderate hypothermia $\left(33^{\circ} \mathrm{C}\right)$ decreases the susceptibility to pacing-induced ventricular fibrillation compared with severe hypothermia $\left(30^{\circ} \mathrm{C}\right)$ by attenuating spatially discordant alternans in isolated rabbit hearts. Zhonghua Minguo Xin Zang Xue Hui Za Zhi 30: 455-465, 2014.

22. Hsieh YC, Lin SF, Lin TC, Ting CT and Wu TJ: Therapeutic hypothermia (30 degrees $C$ ) enhances arrhy thmogenic substrates, including spatially discordant alternans, and facilitates pacing-induced ventricular fibrillation in isolated rabbit hearts. Circ J 73: 2214-2222, 2009.

23. Choy L, Yeo JM, Tse V, Chan SP and Tse G: Cardiac disease and arrhythmogenesis: Mechanistic insights from mouse studies. Int J Cardiol Heart Vasc 12: 1-10, 2016.

24. Tse G, Lai ET, Chan YWF, Yeo JM and Yan BP: What is the arrhythmic substrate in viral myocarditis? Insights from clinical and animal studies. Front Physiol 7: 308, 2016.

25. Stein M, van Veen TA, Remme CA, Boulaksil M, Noorman M, van Stuijvenberg L, van der Nagel R, Bezzina CR, Hauer RN, de Bakker JM and van Rijen HV: Combined reduction of intercellular coupling and membrane excitability differentially affects transverse and longitudinal cardiac conduction. Cardiovase Res 83: 52-60, 2009.

26. Stein M, van Veen TA, Hauer RN, de Bakker JM and van Rijen HV: A 50\% reduction of excitability but not of intercellular coupling affects conduction velocity restitution and activation delay in the mouse heart. PLoS One 6: e20310, 2011.

27. Morley GE, Vaidya D, Samie FH, Lo C, Delmar M and Jalife J: Characterization of conduction in the ventricles of normal and heterozygous $\mathrm{Cx} 43$ knockout mice using optical mapping. J Cardiovasc Electrophysiol 10: 1361-1375, 1999. 
28. George SA, Sciuto KJ, Lin J, Salama ME, Keener JP, Gourdie RG and Poelzing S: Extracellular sodium and potassium levels modulate cardiac conduction in mice heterozygous null for the Connexin43 gene. Pflugers Arch 467: 2287-2297, 2015.

29. Vaidya D, Tamaddon HS, Lo CW, Taffet SM, Delmar M, Morley GE and Jalife J: Null mutation of connexin 43 causes slow propagation of ventricular activation in the late stages of mouse embryonic development. Circ Res 88: 1196-1202, 2001.

30. van Rijen HV, Eckardt D, Degen J, Theis M, Ott T, Willecke K, Jongsma HJ, Opthof T and de Bakker JM: Slow conduction and enhanced anisotropy increase the propensity for ventricular tachyarrhythmias in adult mice with induced deletion of connexin43. Circulation 109: 1048-1055, 2004.

31. Guerrero PA, Schuessler RB, Davis LM, Beyer EC, Johnson CM, Yamada KA and Saffitz JE: Slow ventricular conduction in mice heterozygous for a connexin43 null mutation. J Clin Invest 99 1991-1998, 1997.

32. Thomas SA, Schuessler RB, Berul CI, Beardslee MA, Beyer EC, Mendelsohn ME and Saffitz JE: Disparate effects of deficient expression of connexin 43 on atrial and ventricular conduction: Evidence for chamber-specific molecular determinants of conduction. Circulation 97: 686-691, 1998.

33. Eloff BC, Lerner DL, Yamada KA, Schuessler RB, Saffitz JE and Rosenbaum DS: High resolution optical mapping reveals conduction slowing in connexin43 deficient mice. Cardiovasc Res 51: 681-690, 2001.

34. Christ GJ, Spektor M, Brink PR and Barr L: Further evidence for the selective disruption of intercellular communication by heptanol. Am J Physiol 276: H1911-H1917, 1999.

35. Rüdisüli A and Weingart R: Electrical properties of gap junction channels in guinea-pig ventricular cell pairs revealed by exposure to heptanol. Pflugers Arch 415: 12-21, 1989.

36. Nelson WL and Makielski JC: Block of sodium current by heptanol in voltage-clamped canine cardiac Purkinje cells. Circ Res 68: 977-983, 1991.

37. Balasubramaniam R, Grace AA, Saumarez RC, Vandenberg JI and Huang CL: Electrogram prolongation and nifedipine-suppressible ventricular arrhythmias in mice following targeted disruption of KCNE1. J Physiol 552: 535-546, 2003

38. Knollmann BC, Katchman AN and Franz MR: Monophasic action potential recordings from intact mouse heart: Validation, regional heterogeneity, and relation to refractoriness. J Cardiovasc Electrophysiol 12: 1286-1294, 2001.

39. Gussak I, Chaitman BR, Kopecky SL and Nerbonne JM: Rapid ventricular repolarization in rodents: Electrocardiographic manifestations, molecular mechanisms, and clinical insights. J Electrocardiol 33: 159-170, 2000.

40. Fabritz L, Kirchhof P, Franz MR, Eckardt L, Mönnig G, Milberg P, Breithardt G and Haverkamp W: Prolonged action potential durations, increased dispersion of repolarization, and polymorphic ventricular tachycardia in a mouse model of proarrhythmia. Basic Res Cardiol 98: 25-32, 2003.

41. Wiener $\mathrm{N}$ and Rosenblueth A: The mathematical formulation of the problem of conduction of impulses in a network of connected excitable elements, specifically in cardiac muscle. Arch Inst Cardiol Mex 16: 205-265, 1946.

42. Implantable cardioverter defibrillators for arrhythmias. Review of technology appraisal 11. National Institute for Health and Clinical Excellence (NICE), 2007.

43. Adabag AS, Luepker RV, Roger VL and Gersh BJ: Sudden cardiac death: Epidemiology and risk factors. Nat Rev Cardiol 7 : 216-225, 2010.

44. Chugh SS, Reinier K, Teodorescu C, Evanado A, Kehr E, Al Samara M, Mariani R, Gunson K and Jui J: Epidemiology of sudden cardiac death: Clinical and research implications. Prog Cardiovasc Dis 51: 213-228, 2008.

45. Spray DC and Burt JM: Structure-activity relations of the cardiac gap junction channel. Am J Physiol 258: C195-C205, 1990.

46. Dhillon PS, Gray R, Kojodjojo P, Jabr R, Chowdhury R, Fry CH and Peters NS: Relationship between gap-junctional conductance and conduction velocity in mammalian myocardium. Circ Arrhythm Electrophysiol 6: 1208-1214, 2013.
47. Peters NS: Gap junctions: Clarifying the complexities of connexins and conduction. Circ Res 99: 1156-1158, 2006.

48. Gutstein DE, Morley GE, Tamaddon H, Vaidya D, Schneider MD, Chen J, Chien KR, Stuhlmann H and Fishman GI: Conduction slowing and sudden arrhythmic death in mice with cardiac-restricted inactivation of connexin43. Circ Res 88: 333-339, 2001.

49. Beauchamp P, Choby C, Desplantez T, de Peyer K, Green K, Yamada KA, Weingart R, Saffitz JE and Kléber AG: Electrical propagation in synthetic ventricular myocyte strands from germline connexin43 knockout mice. Circ Res 95: 170-178, 2004.

50. Veeraraghavan R, Salama ME and Poelzing S: Interstitial volume modulates the conduction velocity-gap junction relationship. Am J Physiol Heart Circ Physiol 302: H278-H286, 2012.

51. Hondeghem LM: QTc prolongation as a surrogate for drug-induced arrhythmias: Fact or fallacy? Acta Cardiol 66: 685-689, 2011.

52. Vigmond EJ: The electrophysiological basis of MAP recordings. Cardiovasc Res 68: 502-503, 2005.

53. Vigmond EJ and Leon LJ: Electrophysiological basis of mono-phasic action potential recordings. Med Biol Eng Comput 37: 359-365, 1999.

54. Tse G: Novel conduction-repolarization indices for the stratification of arrhythmic risk. J Geriatr Cardiol, 2016. (Accepted)

55. Tse G: (Tpeak-Tend)/QRS and (Tpeak-Tend)/(QT x QRS): Novel markers for predicting arrhythmic risk in Brugada syndrome. Europace, 2016. (Accepted)

56. Tse G and Yan BP: Novel arrhythmic risk markers incorporating QRS dispersion: QRSd x (Tpeak-Tend)/QRS and QRSd x (Tpeak-Tend)/(QT x QRS). Ann Noninvasive Electrocardiol, 2016. (Accepted).

57. Tse G, Lai ET, Yeo JM and Yan BP: Electrophysiological mechanisms of Bayés syndrome: Insights from clinical and mouse studies. Front Physiol 7: 188, 2016.

58. Tse G, Lai ET, Lee AP, Yan BP and Wong SH: Electrophysiological mechanisms of gastrointestinal arrhythmogenesis: Lessons from the heart. Front Physiol 7, 2016.

59. Tse G, Wong ST, Tse V and Yeo JM: Variability in local action potential durations, dispersion of repolarization and wavelength restitution in aged wild-type and Scn5a+/- mouse hearts modelling human Brugada syndrom. J Geriatr Cardiol, 2016. (Accepted)

60. Tse G, Ali A, Alpendurada F, Prasad S, Raphael CE and Vassiliou V: Tuberculous constrictive pericarditis. Res Cardiovasc Med 4: e29614, 2015.

61. Tse G, Ali A, Prasad SK, Vassiliou V and Raphael CE: Atypical case of post-partum cardiomyopathy: An overlap syndrome with arrhythmogenic right ventricular cardiomyopathy? BJRIcase reports 1: 20150182, 2015.

62. Vassiliou V, Chin C, Perperoglou A, Tse G, Ali A, Raphael C, Jabbour A, Newby D, Pennell D, Dweck D and Prasad S: 93 ejection fraction by cardiovascular magnetic resonance predicts adverse outcomes post aortic valve replacement. Heart 100: A53-A54, 2014

63. Ono Y and Ishiyama A: Non-invasive cardiac functional mapping on disease-model mice-development of high spatial resolution SQUID system for MCG on mice. Teion Kogaku 40: 44-50, 2005.

64. Tse G and Yan BP: Traditional and novel ECG conduction and repolarization markers of sudden cardiac death. Europace, 2016. (In press).

65. Tse G, Yan BP, Chan YW, Tian XY and Huang Y: Reactive oxygen species, endoplasmic reticulum stress and mitochondrial dysfunction: the link with cardiac arrhythmogenesis. Front Physiol 7: 313, 2016.

66. Hu Z, Chen Z, Wang Y, Jiang J, Tse G, Xu W, Ge J and Sun B: Effects of granulocyte colony-stimulating factor on rabbit carotid and swine heart models of chronic obliterative arterial disease. Mol Med Rep, 2016. (Accepted). 